\title{
MESTRADO PROFISSIONAL EM LETRAS E TECNOLOGIA EDUCACIONAL
}

\section{PROFESSIONAL MASTER'S DEGREE IN LANGUAGES AND EDUCATIONAL TECHNOLOGY}

\section{Maria Helena da Nóbrega ${ }^{1}$}

Resumo: As práticas de ensino formal precisam estar em sintonia com as mudanças sociais e profissionais do século XXI. Novas formas de fazer envolvem o uso intensivo de recursos tecnológicos, que entram cada vez mais nas escolas. Este artigo aborda o Mestrado Profissional em Letras e as propostas para o ensino de línguas, incorporando a tecnologia da web 2.0. Após rever aparatos tecnológicos na educação, o texto avalia o cenário da atualidade, divulgando formas de aquisição de conhecimento on-line que ajudam o professor a familiarizar-se com a tecnologia e, a médio prazo, tornar-se produtor de material didático digital.

Palavras-chave: mestrado profissional; tecnologia; ensino de línguas

\begin{abstract}
Formal teaching practices need to be in tune with the social and professional changes of the 21 st century. New ways of doing involve the intensive use of technological resources, which enter more and more into schools. This article addresses the Professional Master's Degree in Languages and its proposals for language teaching, incorporating web 2.0 technology. After reviewing technological devices in education, the text evaluates the current scenario, disseminating forms of online knowledge acquisition that help the teacher to become familiar with the technology and, in the medium term, become a producer of digital didactic material.
\end{abstract}

Keywords: professional master's degree; technology; languages teaching

\section{Introdução}

Olhe ao redor. A maior empresa de transporte urbano do mundo não é proprietária de carros (Uber). A maior empresa de acomodações não possui nenhum hotel (Airbnb). A maior empresa de conteúdo do mundo não cria conteúdo (Facebook). A maior empresa de fotos do mundo não vende máquinas fotográficas (Instagram). A maior empresa de atacado do mundo não tem inventário próprio (Alibaba). (PASCOAL, 2017, p. 19)

\footnotetext{
${ }^{1}$ Doutora em Filologia e Língua Portuguesa, é professora do Mestrado Profissional em Letras e do Programa de PósGraduação em Filologia e Língua Portuguesa, do Departamento de Letras Clássicas e Vernáculas da Universidade de São Paulo (USP). E-mail: mhn135@usp.br
} 
São muitos os processos disruptivos da atualidade, e eles inevitavelmente promovem novas formas de fazer. Os exemplos da epígrafe acima ilustram o que é comum no dia a dia das pessoas. Para acompanhar essas mudanças que, tudo indica, não são modismos passageiros, a escola precisa avançar e superar o imobilismo presente em muitos projetos político-pedagógicos (VETROMILLE-CASTRO; FERREIRA, 2016).

De fato, quais entraves impedem que as mudanças no sistema de produção e nos serviços adentrem o universo das escolas? Uma das respostas pode estar na formação, ainda muito centrada na onisciência do professor. No entanto, tal onisciência não é mais possível, pois a informação está ao alcance de muitos, cabendo então à escola a função de ensinar a avaliar o que as conexões em rede disponibilizam.

De maneira geral, crianças e jovens interagem com a tecnologia, independente de conhecerem ou não o recurso, enquanto os professores solicitam manuais de instrução que digam o que pode ser feito com o programa ou o aplicativo. Isso gera um descompasso entre o mundo real e o mundo segregado da escola.

Enquanto a escola luta e reluta em introduzir as tecnologias atuais na mediação pedagógica, discute quem fica com a chave dos laboratórios de informática e se preocupa com o tempo que os jovens (e as crianças também!) "gastam no computador", as conexões e redes vão se fazendo e as comunidades de aprendizagem - formadas espontaneamente - vão se tornando cada vez mais importantes na distribuição e construção de conhecimentos e saberes. (GOMES, 2016, p. 92)

Ao contrário do que os gestores costumam pregar, a resistência maior não vem dos professores, mas encontra-se impregnada na própria estrutura organizacional escolar. "A resposta não está nas limitações da tecnologia, mas na estrutura impermeável da escola. A escola, tal como a conhecemos, foi desenvolvida no modelo das fábricas do século 18. A fábrica desapareceu ou mudou. A escola resiste" (OLIVEIRA, 2015, p. A2).

Nessas condições, o objetivo deste artigo é mostrar iniciativas precursoras que visam criar caminhos para que o professor supere eventuais lacunas de formação e possa familiarizar-se com práticas educacionais condizentes com os recursos tecnológicos disponíveis para o ensino e a aprendizagem. A justificativa é a necessidade de disponibilizar tais informações aos professores em serviço e em formação, de maneira que eles passem a contextualizar suas aulas para as demandas da atualidade. Pesquisa realizada nos projetos político-pedagógicos de cinco cursos de 
licenciatura de Letras de uma universidade pública do Brasil buscou os termos "tecnologia, CALL, internet, computador, TIC, mídia, digital, web, site, redes sociais" e encontrou o seguinte resultado.

Nenhum dos termos, no entanto, figurava significativamente em um processo de reflexão amplo de formação, mas apenas como um único item do programa de duas disciplinas (há, em todo o projeto político-pedagógico, pelo menos 140 disciplinas voltadas para as licenciaturas). Ainda, curiosamente, todos os alunos entrevistados já haviam cursado as duas disciplinas, mas declararam que o tema não fora abordado durante o semestre. (VETROMILLE-CASTRO; FERREIRA, 2016, p. 161)

Nesse sentido, é extremamente auspicioso constatar a inclusão da disciplina Elaboração de Projetos e Tecnologia Educacional, no Programa de Mestrado Profissional em Letras (Profletras). Trata-se de criar as condições básicas para desenvolver uma habilidade fundamental na atualidade: "Em um mundo em que a produção do conhecimento é coletiva e a comunicação ocorre por meio de uma variedade de diferentes mídias, a capacidade de trabalhar em rede surge como uma habilidade social central e uma competência cultural.” (JENKINS et al, 2009, p. 49) ${ }^{2}$

Na ampla série de recursos tecnológicos disponíveis para a educação, a delimitação restringe-se ao ensino de línguas. A metodologia, de caráter exploratório, ancora-se em pesquisa teórica e prática das aulas do Profletras, em que os alunos são professores da rede pública do ensino fundamental.

Dessa forma, o texto inicialmente caracteriza os programas de mestrado profissional e depois apresenta o Profletras. A seguir, o percurso histórico das tecnologias em sala de aula demonstra aparatos da educação formal e recursos tecnológicos que podem ser utilizados como apoio no ensino de línguas. As práticas interativas de ensino apresentam novas metodologias como a aprendizagem baseada em problemas - e apontam para a conclusão do texto.

\section{Mestrado profissional}

A pós-graduação no Brasil ampliou-se sobretudo a partir da década de 1970, impulsionada pelo Parecer $n^{\circ}$ 977, de 3 de dezembro de 1965, e pela Reforma Universitária de 1968 (ALVES;

\footnotetext{
2 "In a world in which knowledge production is collective and communication occurs across an array of different media, the capacity to network emerges as a core social skill and cultural competency."

Esta e as demais traduções são de responsabilidade da autora deste artigo.
} 
OLIVEIRA, 2014). Os cursos de pós-graduação stricto sensu - mestrado e doutorado - visavam à formação de professores e pesquisadores para o ensino superior, e o aprofundamento das carreiras além da docência era abordado no lato sensu, com cursos de especialização de 360 horas.

Os mestrados profissionais foram criados mais recentemente, em 1998, pela Portaria $\mathrm{n}^{\circ} 80$ da Coordenação de Aperfeiçoamento de Pessoal de Nível Superior (Capes), em resposta à “demanda do mercado de trabalho por profissionais com formação em nível de mestrado, com conhecimentos específicos e aprofundados para a atuação em funções não acadêmicas [...]" (CARMO; ROCHA; FIGUEIREDO FILHO, 2018, p. 5).

Nesse contexto, a proposta inicial dos mestrados profissionais é fomentar a renovação na pós-graduação, de forma a promover a aproximação entre a academia e o mercado. Compartilhando as mesmas prerrogativas do stricto sensu, o diferencial entre esses dois mestrados - o profissional e o acadêmico - é sobretudo no conhecimento aplicado, ou seja: o mestrado profissional busca a aplicação das teorias estudadas para as atividades práticas, as situações reais vividas profissionalmente pelos mestrandos. Esse projeto diferenciado atrai alunos que têm particularidades já descritas pelos pesquisadores.

Nos mais diferentes cursos e instituições de ensino, os ingressantes nessa formação [de mestrado profissional] são, em maior parte, pessoas mais adultas, geralmente profissionais que buscam desempenhar melhorias em suas atuações de trabalho, sejam em escolas, empresas, repartições públicas, movimentos sociais etc. (CARMO; ROCHA; FIGUEIREDO FILHO, 2018, p. 9)

Em 1998, os cursos de mestrado profissional começaram a funcionar com 24 cursos, e em 2018 eles alcançam 765 em todo o Brasil. As avaliações da Capes têm demonstrado que essa ampliação quantitativa tem sido acompanhada de melhora qualitativa (CARMO; ROCHA; FIGUEIREDO FILHO, 2018).

Há mestrados profissionais em diversas áreas: administração, física, direito, economia, história, matemática etc. Aqui se aborda especificamente o mestrado profissional para graduados em Letras e professores da rede pública do ensino fundamental.

\section{Mestrado Profissional em Letras (Profletras)}


Conforme o Regimento do Programa, o Profletras é um curso presencial, em rede nacional, que reúne 42 universidades públicas com a coordenação central na Universidade Federal do Rio Grande do Norte. O foco é capacitar professores de língua portuguesa para o ensino fundamental.

Tal como no mestrado acadêmico, o aluno deve ser aprovado na proficiência de língua estrangeira. Além disso, ele deve completar 24 créditos em disciplinas, ser aprovado no exame de qualificação e no trabalho de conclusão final. Algumas disciplinas do Profletras são: Gêneros discursivos/textuais e práticas sociais; Gramática, variação e ensino; Literatura e ensino; Práticas de oralidade e práticas letradas; Texto e ensino; Ensino da escrita, didatização e avaliação etc.

As disciplinas estão conectadas à área de concentração do Programa: Linguagens $e$ Letramentos. Como os alunos já são professores, o interesse do Profletras é priorizar as questões de aprendizagem, com ênfase em abordagens de ensino, estratégias e práticas que integrem a aprendizagem da língua portuguesa.

Na Universidade de São Paulo, a primeira turma, em 2013, teve 20 alunos. Turmas pequenas cursando as mesmas disciplinas criam dinâmicas muito particulares.

Outra característica observada no perfil desses estudantes [dos cursos de mestrado profissional] é a relação de maior proximidade. Essa rede de aprendizagem horizontal e de compartilhamento mútuo, proporcionada pela troca de experiências dentro de um grupo mais homogêneo, é fortalecida por meio da reciprocidade nas relações e resulta em um processo de conhecimento coletivo do complexo formato das pesquisas aplicadas à formação prática nos mestrandos. (CARMO, ROCHA, FIGUEIREDO FILHO, 2018, p. 9)

Neste artigo interessa destacar a disciplina Elaboração de Projetos e Tecnologia Educacional, cuja ementa ressalta o letramento científico e tecnológico do aluno-professor. Essa disciplina é relevante na formação para que ele adquira uma conceituação mais ampla de tecnologia, reconhecendo-a não apenas no ambiente digital.

\section{Língua escrita: a tecnologia a serviço da comunicação}

A professora entra na sala de aula com entusiasmo e dirige-se ao aluno de sempre:

- Joãozinho, fale três pronomes. 
Para formular essa pergunta, claro que a professora preparou a turma, explicando a morfologia pronominal, a sintaxe, a função de elementos coesivos. Há dias ela vem enchendo o quadro-negro, dividido em seis partes, cada uma com uma lista, anotada com giz, esse suporte técnico-material denominado no início do século XIX de "lápis de ardósia”, "lápis de pedra”, "pena de lousa", "pena de pedra", “grafite de pedra", "giz de pedra” (BARRA, 2013, p. 132).

Quadro 1 - Quadro para listar pronomes em língua portuguesa

\begin{tabular}{|c|c|c|c|c|c|}
\hline $\begin{array}{c}\text { PRONOMES } \\
\text { PESSOAIS }\end{array}$ & $\begin{array}{c}\text { PRONOMES } \\
\text { POSSESSIVOS }\end{array}$ & $\begin{array}{c}\text { PRONOMES } \\
\text { DEMONSTRATIVOS }\end{array}$ & $\begin{array}{c}\text { PRONOMIES } \\
\text { INDEFINIDOS }\end{array}$ & $\begin{array}{c}\text { PRONOMES } \\
\text { RELATIVOS }\end{array}$ & $\begin{array}{c}\text { PRONOMES } \\
\text { INTERROGATIVOS }\end{array}$ \\
\hline & & & & & \\
& & & & & \\
\hline
\end{tabular}

Fonte: elaborado pela autora

Uma beleza de taxonomia; dá gosto ver assim, tão bem arrumadinha na lousa.

Protagonista dessa cena, o quadro-negro começou a ser produzido industrialmente a partir da ardósia preta.

Com base nos registros examinados, o quadro-negro teria surgido entre o final do século XVIII e o início do século XIX. Em ambos os registros, é um instrumento de ensino coletivo, que aparece vinculado à simultaneidade do ensino de ler e escrever. É material que marca o método de ensino de transmissão simultânea e divide espaço, tempo e exercícios com a ardósia de uso individual. (BARRA, 2013, p. 126)

No século XX, esse material rochoso foi substituído por folhas de madeira laminada de tonalidade verde, mas a cor originária permaneceu indelével no nome do objeto: quadro-negro.

A lousa passou a frequentar as salas de aula no século XIX e rapidamente causou uma revolução no mobiliário escolar e nas práticas pedagógicas. Podemos supor que houve rejeição inicial, tanto de professores como de alunos: "isto não vai dar certo"; "não somos obrigados a aceitar"; "como o professor vai escrever na lousa e tomar conta dos alunos ao mesmo tempo?”; “é pra copiar?". 
Como o professor não estava mais sozinho no centro do processo de ensino, a forma de ensinar teve que se adequar a esse recurso. Aulas e aulas já prontas tiveram que ser reformuladas: uma trabalheira imensa. No entanto, a resistência foi vencida pelos benefícios da novidade tecnológica: pela primeira vez era possível mostrar simultaneamente informações visuais para todo o grupo de alunos. Até os gestores ficaram satisfeitos: baixo custo, alto retorno e agrega valor à aula. Negócio fechado!

Rapidamente a lousa se mostrou útil para expor desenhos e o sistema gráfico, a língua escrita - essa sim, um tremendo avanço tecnológico. Por ser tecnologia, tal como Platão destacou, a escrita sempre necessitou de ferramentas, equipamentos, materiais e preparos especiais. Os primeiros escritos ocorreram em argila, barro, pedra, madeira, metal, osso, bambu. Posteriormente o registro passou a ser feito em tecido, papiro, couro e papel, materiais mais flexíveis, que permitiram que as informações escritas fossem dobradas, armazenadas e transportadas mais facilmente.

\section{Da prensa ao livro}

Os primeiros livros impressos em papel surgiram com a invenção da prensa, no século XV. Eram caros e de difícil acesso. Quando começaram a ser utilizados na educação, as críticas eram em relação à perda de retenção da memória, agora transferida para o papel. Um vídeo mostra de forma hilariante a desconfiança aos primeiros livros impressos. Vale a pena conferir a comparação entre pergaminho, livro e computador no vídeo Crônica sobre novas tecnologias - o livro, disponível em https://www.youtube.com/watch?v=PfjyiFU4htw.

A expansão da imprensa e da alfabetização ampliou o mercado do livro, que teve de abdicar do aspecto artesanal para se adequar aos princípios de rentabilidade do sistema capitalista. Em nossos dias, as transformações do livro continuam: audiolivro, livro digital, e-livro, novos suportes que inevitavelmente interferem na produção e recepção das obras, reconfigurando as práticas de ler e escrever.

E-books (1998), Kindle (2007), iPad (2010) provocaram previsões nefastas de que a leitura na tela mataria o livro impresso. No entanto, leitores digitais vêm se formando na ciberliteratura, e começa a surgir também uma literatura propriamente digital, ou seja, que utiliza animações, 
hipertexto etc. Como resultado, o livro impresso, já consolidado, reafirma sua materialidade. O risco maior, portanto, sobretudo em países em desenvolvimento, relaciona-se a saltar tecnologias, sem promover letramento proficiente na etapa anterior.

Fechar a porta da sala para as inovações tecnológicas teria mantido o sistema educacional sem caderno, lápis, caneta, giz colorido. Afastada a tecnofobia e demonstradas as vantagens da lousa, mais dispositivos foram desenvolvidos para a reprodução de cópias: mimeógrafos e equipamentos de fotocópia passaram a auxiliar o professor no ensino da leitura e escrita. $\mathrm{O}$ audiovisual integra essas inovações: televisão e vídeo diversificam as práticas escolares e, se bem utilizados, motivam a aprendizagem.

\section{Na sala de aula}

O ensino de língua estrangeira beneficiou-se enormemente com a inovação tecnológica trazida inicialmente pelas fitas de áudio. O método audiolingual levou ao extremo essa tecnologia, aperfeiçoando os laboratórios de língua que fizeram sucesso a partir da década de 1960. Porém, esse recurso perdeu fôlego quando a crença behaviorista foi abalada, ou seja, quando se demonstrou que exercícios descontextualizados de repetição e memorização produzem falantes inexpressivos em situações comunicativas reais.

Recursos audiovisuais como filmes continuam sendo usados produtivamente para ensinar outras línguas e culturas: vestimenta, gesticulação, expressões fisionômicas, tudo pode ser mostrado com imagens e sons, dispensando descrições verbais.

Com o computador e a internet, lousa interativa, laptop, tablete, celular e smartphone entram na sala de aula e potencializam as oportunidades de aprendizagem: basta estar conectado à rede para ter acesso aos mais variados vídeos, produzidos por aprendizes ou profissionais. Nesse cenário, é possível incentivar os alunos a passarem de espectadores a produtores de conteúdo audiovisual, vivenciando a nova fase da internet, conhecida como 2.0. Diferente da comunicação de um para muitos, a web 2.0 trabalha com o conceito de rede, que conecta todos e espalha a comunicação entre muitos.

É aí que finalmente o aluno de língua estrangeira tem a oportunidade de encontrar o interlocutor autêntico, usando a língua-alvo não como objeto de estudo, mas como 
instrumento de comunicação; e não apenas para receber informação, mas também para transmiti-la, com a oportunidade de interagir com o outro. (LEFFA, 2016, p. 141)

Com uma câmera de vídeo, um computador ou mesmo um celular, é possível produzir roteiros, pequenos filmes ou até o videocurrículo, cada vez mais apreciado no ambiente corporativo. Propostas pedagógicas que solicitam a criação de vídeos dão a sensação de autoria e costumam motivar a participação do aluno, pois ele descobre autenticidade nessa atividade.

A comunicação mediada por computador possibilita práticas linguísticas interativas, essenciais para a aprendizagem de línguas: bate papo, conferências por áudio ou vídeo, fóruns de discussão, sites, blogs, redes sociais. Essas experiências comunicativas autênticas remodelam a aprendizagem de línguas e criam interação que pode levar à autonomia.

\section{Na ponta dos dedos}

Neste século XXI o ambiente virtual de aprendizagem descentraliza-se e pode ser acessado a qualquer momento, de qualquer lugar: educação aberta, aulas compartilhadas, webconferências. $\mathrm{O}$ aspecto positivo é o caráter inclusivo do conhecimento assim compartilhado.

O ser humano é gregário e aprende em sua relação com o outro e com o meio. As redes digitais de relacionamento têm permitido e potencializado novas formas de ser e de estar no mundo, de ensinar e de aprender. Aprende-se em todos os lugares e, nesse sentido, podemos mesmo dizer que há uma escola fora da escola. (GOMES, 2016, p. 83)

Desde 2005, a Web 2.0 ampliou as possibilidades de interação em procedimentos de produção de textos com imagens, links, além dos textos audiovisuais.

Aos poucos o mercado educacional vai assimilando essas ferramentas e reconfigurando novas práticas educativas. Muitos livros didáticos começam a disponibilizar, além do caderno de exercícios, atividades interativas e sugestões de uso na lousa interativa.

Muitas atividades educacionais estão à disposição na internet. Há aulas e palestras que auxiliam o professor na sua educação permanente, bem como jogos com fins pedagógicos. Esses materiais vêm sendo estudados pelos pesquisadores.

Alguns exemplos de Portais que organizam fontes e informações são o Portal do Professor do MEC, principalmente na seção Cursos e Materiais, Links, Jornal do Professor e Espaço da aula. No Portal EducaRede destacam-se os canais Recursos Educativos, Internet na 
escola e Educalinks. No Portal do Instituto Claro destaca-se a seção Observatório com artigos e um banco nacional de pesquisas relacionadas ao uso das tecnologias na Educação. Outro portal com bastante conteúdo para o professor é o Portal da Nova Escola, entre outros. (GONÇALVES, 2009, p. 20)

Tal como ocorre com os demais materiais didáticos, o potencial dessa ferramenta conta com a habilidade e o preparo do professor para a utilização atraente. Além de utilizar, o professor também deve sentir-se apto a criar material digital, o que ainda não acontece, mesmo com aqueles que já usam frequentemente os recursos pedagógicos digitais (VETROMILLE-CASTRO; FERREIRA, 2016). Uma possível explicação é o fato de os cursos de formação não abordarem a produção de material didático para o ambiente digital, fazendo com que o professor não perceba oportunidade empreendedora nessa lacuna de mercado.

Assim, são relevantes as novas diretrizes do Profletras, apresentadas na Resolução ${ }^{\circ}$ 002/2018, que passa a aceitar como trabalho de conclusão final não apenas a dissertação escrita, mas também material didático em vídeo ou software, estendendo o letramento digital do docente para além das aulas de Tecnologia Educacional. Essa experiência pode incentivá-lo a tornar-se produtor de material didático digital em língua portuguesa.

Complementando a citação anterior, apresento a seguir uma pequena mostra de material com diferentes tipos de atividades interativas. Todos eles ajudam a desenvolver alguma habilidade requerida na maioria das profissões da atualidade e, portanto, podem ser úteis aos professores: saber analisar dados, comunicar-se bem, ter inteligência emocional, entender de economia, ser criativo e inovador, sentir-se confortável com tecnologia, falar outras línguas, manter o foco, ser capaz de liderar, conseguir se adaptar a mudanças (REIS, 2018).

\section{Quadro 2 - Materiais digitais para o professor}

\begin{tabular}{l} 
Portal do Professor: planos de aula, cursos e grupos de discussão. O portal oferece muito material multimídia, \\
além de fóruns para a colaboração em rede. \\
http://portaldoprofessor.mec.gov.br/index.html \\
\hline TV Escola: vídeos, documentários e entrevistas sobre diferentes áreas temáticas subsidiam o trabalho do \\
professor. Nos Percursos Educativos, além dos conteúdos do ensino básico, há uma relação das últimas \\
questões do Exame Nacional do Ensino Médio (ENEM). \\
http://tvescola.mec.gov.br/tve/home \\
Coursera: cursos gratuitos oferecidos por várias universidades do mundo. A maioria das videoaulas é em \\
inglês, com legendas em português, mas crescem generosamente os cursos oferecidos em português.
\end{tabular}




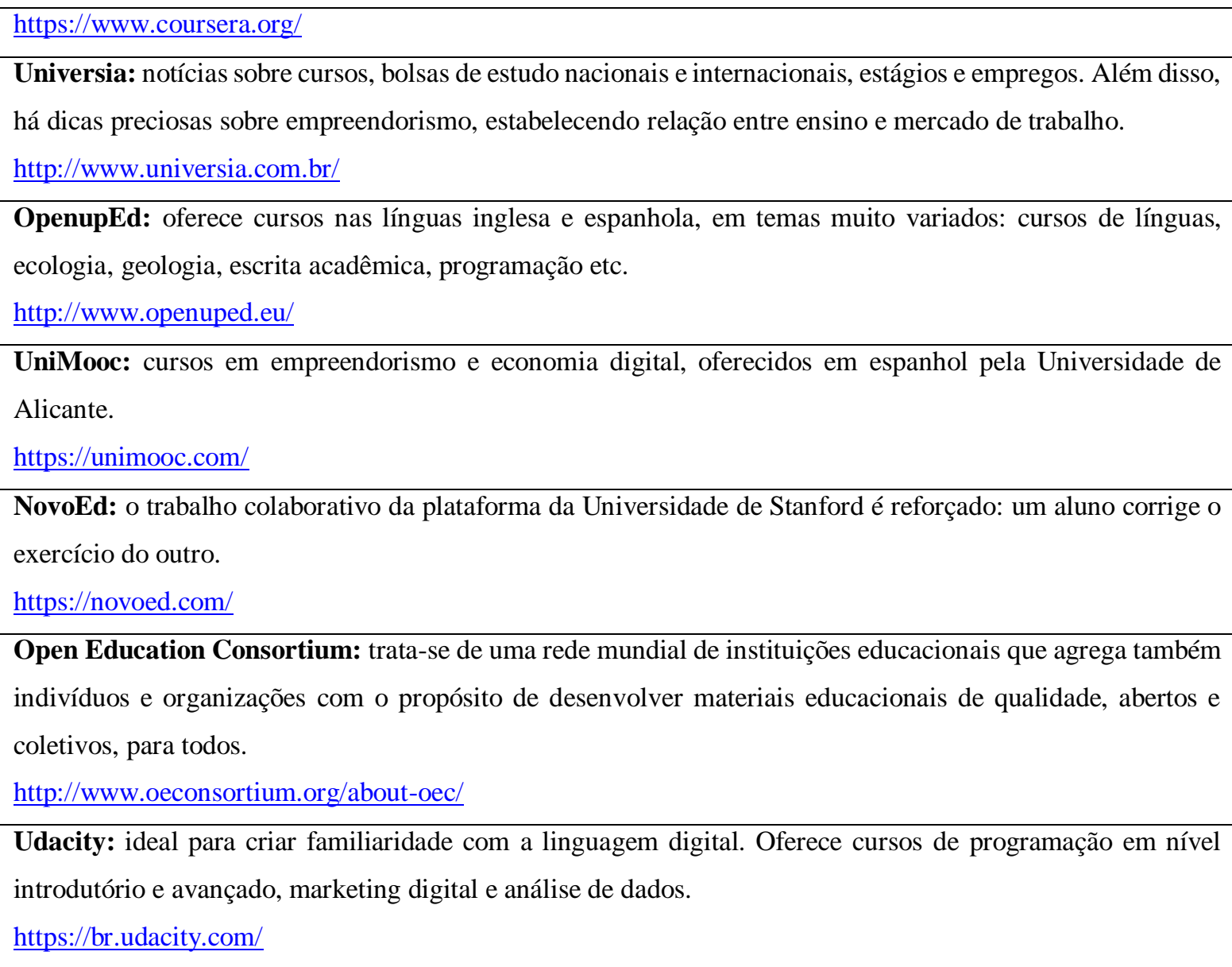

Fonte: elaborado pela autora

A maioria desses cursos é gratuito, mas há os que cobram para emitir certificado de conclusão. Como as possibilidades são muito variadas e é impraticável seguir todas as propostas, o professor zeloso deve escolher a partir de seus interesses e necessidades de aprimoramento. No caso da linguagem digital da Udacity, a sugestão é que todos tenham alguma proficiência que se situe entre o programador profissional e o mero usuário.

"Cada vez mais os profissionais precisarão entender um pouco de tecnologia para enxergar dentro do seu rol de atividades onde ela pode fazer com que ganhe eficiência, qualidade e competitividade", diz Marcelo Redoschi de Carvalho, superintendente de atração, seleção e escola de negócios do Itaú. Um curso introdutório de programação, então, é bem-vindo. (REIS, 2018, p. 6)

Dominar algumas ferramentas de tecnologia criará autonomia para que o professor seja produtor de materiais úteis às suas aulas. 
Essa gama de cursos livremente disponibilizados na internet demonstra claramente que o conhecimento saiu da sala de aula e está sendo formalizado por outras vias. Positivamente, reconhece-se o alto poder de inclusão da tecnologia, que amplia o número de participantes e produtores do conhecimento. No tocante às críticas, "talvez, uma das mudanças mais alarmantes na perspectiva dos adultos é o declínio percebido na atenção dos jovens após a ascensão da mídia digital. A atenção é indubitavelmente uma habilidade cognitiva importante” (JENKINS et al., 2009, p. 34$)^{3}$.

Vale considerar, inclusive, que o próprio termo "educação a distância" parece remeter apenas à distância física, sem que se considere a distância temporal (síncrona; assíncrona) ou a distância interativa, assim definida:

A distância interativa, ou operacional, se relaciona diretamente à participação do aluno no processo, e informa se este é operacionalmente ativo ou passivo. Quanto maior a interatividade do aluno, menor é a distância operacional. Assim como na classificação das demais distâncias [física e temporal]: há também aqui três tipos de distâncias interativas: professor-aluno (aula expositiva $\mathrm{X}$ aula interativa); aluno-material (material passivo $\mathrm{X}$ material interativo); aluno-aluno (trabalho individual $\mathrm{X}$ trabalho cooperativo). (TORI, 2002, p. 4)

O fato é que os recursos tecnológicos tendem a ser cada vez mais incorporados no ensino formal, e esses novos contextos de produção do conhecimento demandam um reposicionamento dos papéis dos atores principais do processo de ensino e aprendizagem: professor e aluno.

\section{Práticas interativas de ensino}

Nesses novos cenários comunicativos, a transmissão cede ligar à interatividade. Isso quer dizer que os parâmetros são diferentes daqueles com os quais o professor estava acostumado a lidar quando incorporou o rádio, a televisão e o jornal nas práticas pedagógicas.

Isso significa modificação radical no esquema clássico da informação baseado na ligação unilateral emissor - mensagem - receptor: a) o emissor não emite mais, no sentido que se entende habitualmente, uma mensagem fechada, oferece um leque de elementos e possibilidades à manipulação do receptor; b) a mensagem não é mais "emitida", não é mais um mundo fechado, paralisado, imutável, intocável, sagrado, é um mundo aberto,

\footnotetext{
3 "Perhaps one of the most alarming changes in adults' view is the perceived decline in young people's attention spans with the rise of digital media. Attention is undoubtedly an important cognitive ability".
} 
modificável na medida em que responde às solicitações daquele que a consulta; c) o receptor não está mais em posição de recepção clássica, é convidado à livre criação, e a mensagem ganha sentido sob sua intervenção. (SILVA, s. d., p. 64)

Várias propostas têm surgido para trazer respostas aos novos papéis do professor e do aluno em contextos colaborativos de produção do conhecimento. A intenção é promover um certo afastamento do professor, colocando o aluno como responsável pelo seu próprio aprendizado. No geral, defende-se que o ensino e a aprendizagem dependem das interações entre os indivíduos e das tecnologias que eles utilizam.

O conhecimento é visto como um processo, fluido e dinâmico, fluindo entre redes de trabalho de humanos e seus artefatos. Conforme esse conhecimento flui e se torna parte da rede, ele está aberto a múltiplas interpretações e alterações. O conhecimento reside nessas redes de trabalho, sem que qualquer indivíduo necessariamente o possua, e ele pode ser armazenado em uma variedade de formatos digitais. (GOLDIE, 2016, p. 5) ${ }^{4}$

A superação do ensino centrado apenas na transmissão, marcadamente cristalizado em aulas expositivas, e do aprendizado como memorização aponta que o conhecimento é uma construção sem fronteiras.

Na perspectiva da interatividade, o professor pode deixar de ser um transmissor de saberes para converter-se em formulador de problemas, provocador de interrogações, coordenador de equipes de trabalho, sistematizador de experiências e memória viva de uma educação que, em lugar de prender-se à transmissão, valoriza e possibilita o diálogo e a colaboração." (SILVA, s. d., p. 64-65)

Outras práticas que procuram ser responsivas às questões profissionais e educacionais do século XXI são a aprendizagem baseada em problemas e aprendizagem baseada em projetos. Em ambas as perspectivas, a aprendizagem vai estar diretamente relacionada aos interesses e experiências dos aprendizes. Essas propostas conciliam-se perfeitamente com a educação a distância e o uso variado de multimídias.

Colocada sob este grande volume de novidades, há sentido na busca de uma "pedagogia digital" que seja mais adequada aos ambientes virtuais de aprendizagem. Se não mudam os atores, continuam a existir o professor e o aluno, mudam de modo significativo as formas de aprender - aprender a aprender, aprender pela pesquisa, aprender pelo erro, aprender de

\footnotetext{
4 "Knowledge is viewed as a process, fluid and dynamic flowing through networks of humans and their artefacts. As it flows through and becomes part of the network it is open to multiple interpretations and change. Knowledge resides within networks, without any individual necessarily possessing it, and it can be stored in a variety of digital formats."
} 
forma colaborativa, aprender fazendo e, uma perspectiva já tratada nos ambientes tradicionais, aprender a solucionar problemas - esta proposta nos parece entrar na ordem do dia. (MUNHOZ, 2015, p. 82-83)

Esse ambiente de colaboração em rede diverge do modelo competitivo e individual da estrutura educacional tradicional, que ainda procura o erro para penalizar o aluno, atribuindo-lhe nota baixa. Aliás, todo o sistema de avaliação precisa ser repensando nas propostas interativas e colaborativas de ensino. São muitas mudanças em jogo, que não podem depender apenas do professor.

Nesse contexto de mudança paradigmática, as universidades, seus gestores e seus professores precisam refletir sobre as reais necessidades que os alunos irão enfrentar em suas profissões e em suas vidas. A sociedade do conhecimento vem trazendo novos enfrentamentos para a população, pois as exigências na formação de cada área profissional tendem a mudar, e o aluno precisa estar preparado para essas transformações. Portanto, a formação deve contemplar um espaço aberto para o diálogo, para a busca incessante do novo, do desejo de pesquisar e tornar-se autônomo e produtivo. (BEHRENS, s. d., p. 76)

Uma nova configuração física da sala de aula poderia acomodar as práticas interativas, além de ter investimento de baixo custo. Em vez de carteiras individuais, mesas permitiriam a acomodação de pequenos grupos e promoveriam o início das alterações que poderiam conduzir a reconfigurações dos papéis dos alunos e do professor.

\section{Conclusão}

Este artigo mostrou que as tecnologias educacionais não começam com a internet, mas vêm desde as primeiras possibilidades de registro escrito: o quadro-negro, o giz, suportes técnicomateriais que iniciaram o ensino transmitido de forma simultânea para vários alunos. Cadernos e livros tornam possíveis a conservação do registro, hoje expandida em algoritmos. A lousa interativa, o computador, o celular, toda novidade sempre foi recebida com receio e críticas desfavoráveis.

A questão principal é perceber que professores bem formados e auxiliados por uma boa implementação tecnológica podem acompanhar os alunos e auxiliá-los de forma personalizada, dando subsídios para que cada um alcance as melhores metas dentro dos seus interesses 
particulares. A prática tem demonstrado que o aluno aprende o que quer, quando está motivado para aprender.

Os projetos pedagógicos no geral repetem o conteúdo ortodoxo dos cursos tradicionais na área, e inovar é um risco a ser evitado. Por isso é auspicioso o projeto pedagógico do Profletras, programa em rede nacional, atualmente na quinta edição. Pesquisa sobre os egressos dos mestrados profissionais já demonstrou que o curso forma "um mestre capaz de atuar habilmente em sua área de formação, com intervenções em sua função profissional, de maneira efetiva e exitosa [...]" (CARMO, ROCHA, FIGUEIREDO FILHO, 2018, p. 10).

O Programa oferece, dentre as temáticas de fundamentação, a disciplina Elaboração de Projetos e Tecnologia Educacional. Assim, os professores do ensino fundamental alcançam formação em pesquisa aplicada à sala de aula e em tecnologia educacional, seguido de outros temas fundamentais na atualidade, como as teorias de linguagem e produção textual.

O que faz a diferença é o humano - o professor e o aluno: a formação daquele; o interesse deste. A tecnologia, se mal utilizada, mais prejudica do que ajuda. Mesmo o celular, que tem sido amplamente utilizado até para a pesquisa, pode prejudicar a concentração quando usado exageradamente e por longos períodos (SAHLBERG, 2018).

Finalmente, precisamos possibilitar formação para que os professores estejam habilitados não apenas a utilizar a tecnologia disponível, mas também a serem produtores no ambiente digital. A criação de exercícios, jogos e plataformas vem crescendo no ensino de línguas e deve ser incentivada, para que alcance resultados mais produtivos no que ensina. Duolingo, por exemplo, é um site educacional que reúne muitos aprendizes de línguas, mas seu interesse é implementar a tradução na internet. Em suas pesquisas, Leffa (2016) analisou esse material: "Minha impressão pessoal ao usar o Duolingo como aluno é ambígua: do lado tecnológico, um exemplo qualificado de usabilidade; do lado pedagógico, volta a um passado remoto (...): a ênfase na tradução de frases descontextualizadas". (p. 151)

Algumas propostas, aliás, são meras transposições de exercícios tradicionais centrados na forma, demonstrando que as criações no ambiente digital precisam ser melhoradas. Tem até pronomes. Falando nisso, e o Joãozinho, hein?! Instado a citar três pronomes, ele olhou para a lousa, suporte material que pode ser usado para manter a disciplina e passividade dos alunos, viu a lista de pronomes e respondeu para a professora: 
- Quem? Eu? Por quê?

\section{Referências bibliográficas}

ALVES, Miriam F.; OLIVEIRA, João F. de. Pós-graduação no Brasil: do regime militar aos dias atuais. In: Revista Brasileira de Política e Administração da Educação, v. 30, n. 2, mai/ago. 2014. p. 351-376. Disponível em https://seer.ufrgs.br/rbpae/article/viewFile/53680/33095 Acesso em 11 dez. 2018.

BARRA, Valdeniza M. L. da. A lousa de uso escolar: traços da história de uma tecnologia da escola moderna. In: Educar em Revista. Curitiba: Editora UFPR, jul./set. 2013. p. 121-137. Disponível em http://www.scielo.br/pdf/er/n49/a08n49.pdf Acesso em 20 maio 2018.

BEHRENS, Marilda A. Tecnologia interativa a serviço da aprendizagem colaborativa num paradigma emergente. In: Tecnologias na escola - MEC. s. d. p. 74-78. Disponível em http://portal.mec.gov.br/seed/arquivos/pdf/2sf.pdf Acesso em 30 abr. 2018.

CARMO, Erinaldo F.; ROCHA, Enivaldo C. da; FIGUEIREDO FILHO, Dalson B. Cinco anos do MPPP-UFPE e 20 anos dos mestrados profissionais no Brasil. In: Espaço Público, v. 2, p. 3-17, dez. $2018 . \quad$ Disponível em https://periodicos.ufpe.br/revistas/politicaspublicas/article/view/238590/30373 Acesso em $11 \mathrm{dez}$. 2018.

GOLDIE, John G. S. Connectivism: a knowledge learning theory for the digital age?. Medical Teacher, 38 (10), 2016. p. 1064-1069. Disponível em http://eprints.gla.ac.uk/118043/9/118043.pdf Acesso em 19 maio 2018.

GOMES, Luiz F. Redes sociais e escola: o que temos de aprender? In: ARAÚJO, Júlio; LEFFA, Vilson (Orgs.). Redes sociais e ensino de línguas: o que temos de aprender? São Paulo: Parábola, 2016. p. 81-92.

GONÇALVES, Mila. Redes de colaboração e aprendizagem. Portais educacionais e redes sociais - novos espaços para ensinar e aprender. In: Tecnologias digitais na educação. MEC. Ano XIX, boletim 19, nov.-dez. 2009. p. 18-23. Disponível em http://portaldoprofessor.mec.gov.br/storage/materiais/0000012178.pdf Acesso em 30 abr. 2018.

JENKINS, Henry et al. Confronting the challenges of participatory culture: media education for the 21st century. Chicago: The MacArthur Foundation, 2009. Disponível em https://www.macfound.org/media/article_pdfs/JENKINS_WHITE_PAPER.PDF. Acesso em 19 maio 2018.

LEFFA, Vilson. Redes sociais: ensinando línguas como antigamente. In: ARAÚJO, Júlio; LEFFA, Vilson (Orgs.). Redes sociais e ensino de línguas: o que temos de aprender? São Paulo: Parábola, 2016. p. 137-153. 
MUNHOZ, Antonio S. Aprendizagem baseada em problemas: ferramenta de apoio do docente no processo de ensino e aprendizagem. São Paulo: Cengage Learning, 2015.

OLIVEIRA, João B. A. e. Produtividade e tecnologias na educação. In: O Estado de S. Paulo. 27/maio/2015. p. A2. Disponível em http://www.semesp.org.br/imprensa/produtividade-etecnologia-na-educacao/ Acesso em 30 abr. 2018.

PASCOAL, Candice. Seu sonho tem futuro. São Paulo: Gente, 2017.

REIS, Fernanda. Dez cursos que ampliam o lado polivalente de todo profissional. In: Folha de $S$. Paulo. 262 abr. 2018.2018 Disponível http://www1.folha.uol.com.br/sobretudo/carreiras/2018/04/1965669-dez-cursos-que-ampliam-olado-polivalente-de-todo-profissional.shtml Acesso em 19 maio 2018.

SAHLBERG, Pasi. Lições finlandesas 2.0: o que a mudança educacional na Finlândia pode ensinar ao mundo? São Paulo: Sesi, 2018.

SILVA, Marco. Internet na escola e inclusão. In: Tecnologias na escola-MEC. s. d. p. 62-68. Disponível em http://portal.mec.gov.br/seed/arquivos/pdf/2sf.pdf Acesso em 30 abr. 2018.

TORI, Romero. Métricas para uma educação sem distância. In: Revista Brasileira de Informática na Educação, $\quad$ v. $10, \quad$ n. $\quad 2, \quad 2002 . \quad$ Disponível em http://www.lbd.dcc.ufmg.br/colecoes/rbie/10/2/001.pdf Acesso em 11 dez. 2018.

VETROMILLE-CASTRO, Rafael; FERREIRA, Kathleen S. Redes sociais na formação de professores de línguas. In: ARAÚJO, Júlio; LEFFA, Vilson (Orgs.). Redes sociais e ensino de línguas: o que temos de aprender? São Paulo: Parábola, 2016. p. 155-170.

Recebido em 24 de maio de 2018. Aceito em 17 de dezembro de 2018. 